\title{
A Localização Geográfica como Recurso Organizacional: Utilização de Sistemas Especialistas para Subsidiar a Tomada de Decisão Locacional do Setor Bancário
}

\author{
Geographical Location as an Organizational Resource: Use of Computational \\ Techniques to Subsidize Location Decision Making in the Banking Industry
}

Ana Maria dos Santos Carnasciali *

E-mail: ana.carnasciali@gmail.com Ministério do Planejamento, Orçamento e Gestão Curitiba, PR, Brasil.

Luciene Stamato Delazari E-mail: luciene@ufpr.br Universidade Federal do Paraná Curitiba, PR, Brasil.

* Endereço: Ana Maria dos Santos Carnasciali

Rua Luiz Homann, 356, casa 04, São Braz, Curitiba/PR, 82310-100.

Copyright (C) 2011 RAC. Todos os direitos, até mesmo de tradução, são reservados. É permitido citar parte de artigos sem autorização prévia, desde que seja identificada a fonte. 


\title{
Resumo
}

A localização geográfica de um ponto comercial em qualquer setor constitui um recurso físico que, somado aos recursos financeiros, de capital humano, organizacional, reputação e tecnológico podem levar a organização a uma condição ímpar em relação aos concorrentes. Decidir sobre a melhor localização do ponto comercial é uma das tarefas mais importantes a ser realizada; porém necessita de estudos criteriosos, e não apenas parâmetros baseados no bom senso e experiência dos especialistas. O que se propõe neste trabalho é a integração de um Sistema de Informações Geográficas (SIG) e um Sistema Especialista (SE), a fim de subsidiar a tomada de decisões com relação à escolha da melhor localização para a abertura de uma agência bancária, neste caso do HSBC Bank Brasil S/A, de tal forma que essa melhor localização constitua um recurso físico competitivo para a organização. A utilização da informação geográfica como recurso físico necessita que diferentes variáveis sejam equacionadas até se obter a melhor solução. Neste trabalho, foi desenvolvido um sistema denominado Sistema de Prospecção de Imóveis para o Setor Bancário (SPI), que permite detalhar tais variáveis em termos de valor, raridade, dificuldade em serem imitadas e substituídas. Partindo-se de que a visão baseada em recursos (VBR) enfatiza a escolha estratégica, mediante a valorização de importantes ações, como identificar, desenvolver e desdobrar recursos-chave pela gerência da organização para maximizar os retornos, também foi realizada uma análise dos imóveis prospectados em termos de vantagem competitiva, concluindo-se que a VBR é o elemento que contribui para o SPI, pois eleva a sua capacidade de análise, indo além da questão de localização, ou seja, a VBR permite que os imóveis prospectados sejam examinados em termos de vantagem competitiva.

Palavras-chave: visão baseada em recurso; sistema de informações geográficas; sistema especialista; setor bancário; integração de sistemas.

\begin{abstract}
The location of a business site is a material resource and, along with its financial and technological resources, may provide a company with a distinguished position in comparison with its competitors. Deciding on the best location of a business site is a major task and requires several studies This paper proposes the integration of a Geographic Information System and an Expert System (SES) to support decision-making regarding the choice of the best location to open a branch of bank so that location constitutes a competition material resource for the organization. In this paper, we develop a system called the Realty Prospecting System for the Banking Sector (RPS), which allows these variables to be detailed in terms of value, rarity and difficulty to imitate and substitute. Assuming that the resource based view (RBV) emphasizes the strategic choice by the recovery of important actions such as identifying, developing and deploying key resources for the management of the organization to maximize returns, an analysis of the prospected properties in terms of competitive advantage was also conducted, concluding that the RBV is the element that contributes to the SPI. It increases ability to analyze the system beyond the question of location, i.e., the RBV allows prospected properties to be examined in terms of competitive advantage.
\end{abstract}

Key words: resource-based view; geographical information system; expert system; banking industry; system integration. 


\section{Introdução}

O entendimento dos fatores que determinam a vantagem competitiva é provavelmente o tema central dos estudos sobre estratégia (Porter, 1991). Como contribuições da área de estratégia, destacam-se especialmente os trabalhos de Porter $(1986,1996)$ e aqueles que associam a visão baseada em recursos (VBR), tais como o de Wernerfelt (1984) e Barney (1991). A abordagem baseada em recursos é desafio para as organizações, uma vez que se faz necessário alterar a forma de confrontar a concorrência, ou seja, não mais por meio de uma adaptação ao ambiente concorrencial, com foco nos segmentos de mercado, fornecedores, entre outros, mas essencialmente ao ambiente interno da organização, por meio de seus recursos, capacidade de inovação e competências, de modo a beneficiar o desempenho organizacional e consequentemente seus produtos e serviços.

Um recurso é elemento considerado importante para uma empresa, por contribuir para aumentar a sua competitividade de acordo com suas características (valioso, raro, difícil de ser imitado ou substituído), e que não pode ser repassado a outras empresas sem custos. Barney (1996) e Barney e Hesterly (1996) propõem a divisão dos recursos nas seguintes categorias: financeiros, físicos (localização geográfica, instalações); organizacionais (planejamento, controle) e humanos (experiência, treinamento, inteligência). Grant (1996) acrescenta à divisão acima mais duas categorias: reputação (associação da empresa com produtos de qualidade, confiança, reconhecimento de produto); e recursos tecnológicos (software, hardware, equipamentos e maquinários).

Os autores destacam a localização geográfica como recurso físico. A localização geográfica é recurso; soma-se aos demais; estes recursos financeiros, de capital humano, organizacional, reputação e tecnológico podem levar a organização a uma condição ímpar em relação aos concorrentes. Entretanto, decidir a localização requer decisões estratégicas que necessitam de estudos criteriosos, e não apenas parâmetros baseados no bom senso e experiência dos especialistas. Com o desenvolvimento tecnológico, diversas técnicas computacionais estão disponíveis, como os Sistemas de Informações Geográficas (SIG) e os Sistemas Especialistas (SE).

O que se propõe neste trabalho é a integração de um SIG e um SE, a fim de subsidiar a tomada de decisões com relação à escolha da melhor localização para a abertura de uma agência bancária, neste caso o HSBC Bank Brasil S/A - Banco Múltiplo, departamento de Administração de Imóveis (DAI), abrangendo o município de Curitiba/PR.

Deste modo pretende-se contribuir para a pesquisa na área, considerando que o desenvolvimento de sistema que integre SIG e SE, aliado às análises de vantagem competitiva, no auxílio à tomada de decisão, poderá ser incorporado à estratégia de atuação de qualquer organização, seja ela financeira, comercial, educacional, de saúde, isto é, o sistema independe da sua área de atuação em face dos seus concorrentes.

O trabalho está desenvolvido nos seguintes itens: o segundo item trata da fundamentação teórica, com os conceitos de Visão Baseada em Recursos, Sistemas de Informações Geográficas e Sistemas Especialistas. O terceiro item trata da delimitação e execução da pesquisa, em que se aborda a organização pesquisada, bem como todo o desenvolvimento do trabalho. No quarto item são feitas as análise dos imóveis prospectados em termos de vantagem competitiva; por fim, no quinto item estão as conclusões e recomendações.

\section{Fundamentação Teórica}

\section{Visão baseada em recursos}

Seu precursor foi Wernerfelt, autor do artigo A Resource-based View of the Firm, escrito em 1984. A visão baseada em recursos procura explicar o desempenho superior das organizações e as 
estratégias que permitiram alcançá-lo mediante a análise dos recursos de uma organização, sejam eles tangíveis ou intangíveis. Os recursos correspondem aos ativos tangíveis e intangíveis, que são vinculados de forma semi-permanente à empresa, que não podem ser transferidos a outra sem custos e, que a capacita a conceber e executar estratégias de modo a obter e/ou manter certa posição competitiva (Barney, 1992, 1994, 1996; Barney \& Hesterly, 1996; Wernerfelt, 1984).

Barney (1991) define recursos como todos os ativos, capacidades, processos organizacionais, atributos da empresa, informações, conhecimentos, controlados pela empresa e que lhe permitem compreender e colocar em ação as estratégias suscetíveis de aumentar sua eficácia e sua eficiência na concepção e implementação de estratégias. Entretanto, nem todos os recursos são fontes de vantagens competitivas sustentáveis (Barney, 1991; Peteraf, 1993). A vantagem competitiva, de acordo com Barney (1991), corresponde à criação de valor para a firma durante a implementação de uma estratégia que não é implementada simultaneamente por nenhum concorrente atual ou potencial. Quando os concorrentes não são capazes de duplicar os benefícios da estratégia implementada pela firma, tem-se, então, a vantagem competitiva sustentável. Uma vantagem competitiva sustentável pode ser obtida, se a firma eficientemente desenvolve recursos-chave cujas características (Barney, 1992, 1996) são explicitadas abaixo.

1. Valiosos: os recursos devem explorar oportunidades e/ou neutralizar ameaças do ambiente, permitindo a redução dos custos ou o incremento de receitas da empresa.

2. Raros: os recursos devem ser raros entre os competidores atuais e potenciais da empresa.

3. Difíceis de serem imitados: isto ocorre quando empresas que não possuem determinado recurso enfrentariam uma desvantagem de custo para obtê-lo, em comparação com firmas que já o possuem.

4. Difíceis de serem substituídos: quando não existe equivalente estratégico que possa desenvolver a mesma estratégia, mesmo que de maneira distinta, mas que não seja raro e imperfeitamente imitável entre os concorrentes.

De acordo com Barney (1992), é possível verificar o grau de vantagem competitiva permeada pelo recurso, conforme a Tabela 1.

Tabela 1

\section{Implicações Competitivas}

O recurso é...

Possuído pela Empresa Valioso Raro Difícil de ser Imitado Difícil de ser Substituído Implicações Competitivas

\begin{tabular}{|c|c|c|c|c|c|}
\hline Não & - & - & & & $\begin{array}{c}\text { Desvantagem } \\
\text { Competitiva (DC) }\end{array}$ \\
\hline Sim & Não & - & - & - & $\begin{array}{c}\text { Desvantagem } \\
\text { Competitiva (DC) }\end{array}$ \\
\hline Sim & Sim & Não & - & - & $\begin{array}{c}\text { Paridade Competitiva } \\
\text { Temporária (PCT) }\end{array}$ \\
\hline Sim & Sim & Sim & Não & - & $\begin{array}{l}\text { Vantagem Competitiva } \\
\text { Temporária (VCT) }\end{array}$ \\
\hline Sim & Sim & Sim & Sim & Não & Paridade Competitiva (PC) \\
\hline Sim & Sim & Sim & Sim & $\operatorname{Sim}$ & $\begin{array}{c}\text { Vantagem Competitiva } \\
\text { Sustentável (VCS) }\end{array}$ \\
\hline
\end{tabular}

Nota. Fonte: adaptado de Barney, J. (1992). Integrating organizational behavior and strategy formulation research: a resource-based analysis (p. 215). In P. Shrivastava, A. S. Huff, \& J. E. Dutton (Eds.), Advances in strategic management (Vol. 8, pp. 203-227). Greenwich: Jai Press. 
Barney (1996) e Barney e Hesterly (1996) propõem a divisão dos recursos nas seguintes categorias: financeiro, físico, de capital humano e organizacional. Os recursos financeiros incluem todos os tipos de recursos financeiros que possibilitam que a organização conceba e execute estratégias. Os recursos físicos incluem fábricas, localização geográfica, acesso à matéria-prima. Os recursos de capital humano incluem o treinamento, a experiência, a inteligência, o conhecimento, o julgamento, insights. Os recursos organizacionais incluem a estrutura formal da empresa, os sistemas formais e informais de planejamento, controle e coordenação, a cultura, bem como relações entre grupos pertencentes à firma e também com outros de fora. Além disso, segundo Grant (1996) a reputação da empresa e os recursos tecnológicos também são elementos importantes a serem utilizados pelas organizações.

\section{Sistemas de informações geográficas}

Com o desenvolvimento de sistemas computacionais, tornou-se possível a automatização de tarefas antes realizadas manualmente: facilitou-se a realização das análises espaciais, pela possibilidade de integração de dados de diversas fontes, bem como da criação de bancos de dados georreferenciados. Estes sistemas são denominados Sistemas de Informações Geográficas (SIG).

Segundo Câmara e Queiroz (2006), o termo SIG é aplicado em sistemas que realizam o tratamento computacional de dados geográficos e recuperam informações não apenas com base em suas características alfanuméricas, mas também de sua localização espacial.

São várias as definições de SIG encontradas na literatura; cada uma reflete a multiplicidade de usos possíveis. Dentre as diversas, destacam-se para o contexto deste trabalho a definição de Burrough e McDonnell (1998, p. 11), segundo a qual SIG é um "conjunto de ferramentas para coletar, armazenar, recuperar, transformar e representar visualmente dados espaciais"; a definição de Cowen (1988, p. 1554) é "um sistema de apoio à decisão que envolve a integração de dados espacialmente referenciados, em um ambiente para resolução de problemas".

Com base nessas definições, pode-se considerar que no SIG se encontra um recurso tecnológico útil para as análises espaciais e de apoio ao processo de tomada de decisão. Destaca-se entre as diversas possibilidades de aplicações as que estão relacionadas ao planejamento de uma rede de agências bancárias. Dados referentes às localizações das agências bancárias e postos de atendimento bancário e eletrônico, tanto da própria rede como da concorrência, dados socioeconômicos, como renda, densidade demográfica, entre outros, quando disponíveis nas instituições bancárias apenas em forma de relatórios e/ou mapas em papel, dificultam as análises espaciais, uma vez que tais análises requerem a combinação entre os diversos dados. O uso do SIG facilita as análises espaciais, sendo importante ressaltar que essa facilidade é devida à sua capacidade para combinar diferentes dados.

\section{Sistemas especialistas}

O professor Edward Feigenbaum, da Universidade de Stanford, segundo Waterman (1983) e Harmon e King (1988), é um dos principais pesquisadores de sistemas especialistas (SE). Feigenbaum, citado por Waterman (1983) e Harmon e King (1988), define SE como programa inteligente de computador que usa conhecimento e procedimentos inferenciais (processo pelo qual se derivam novos fatos de fatos conhecidos), para resolver problemas que requerem perícia humana para a sua solução. Waterman (1986) define SE como programas de computadores que manipulam conhecimento para resolver problemas eficientemente em uma área específica.

Um sistema especialista é composto essencialmente por uma base de conhecimento, que consiste em extensa coleção de informações e conhecimentos sobre um domínio específico; e por uma máquina (processador) de inferência, que manipula o conteúdo daquela base para produzir conclusões ou julgamentos (Genaro, 1986). A base de conhecimento contém fatos e regras ou outra representação do conhecimento, que se usam na tomada de decisões. A máquina de inferência decide como aplicar as 
regras e em que ordem, a fim de deduzir novos conhecimentos. Como a base de conhecimento é separada da máquina de inferência, torna-se fácil projetar procedimentos para manipulá-la.

O projeto de um sistema especialista envolve as seguintes etapas: avaliação do problema, aquisição de conhecimento, projeto, testes, documentação e manutenção (Durkin, 1994). A parte mais sensível no desenvolvimento de um sistema especialista é, certamente, a aquisição de conhecimento (Bittencourt, 1998). A aquisição de conhecimento envolve a extração e a formalização do conhecimento de um especialista para uso em um sistema especialista; o engenheiro do conhecimento auxilia o especialista em articular sua experiência em termos de regras práticas e decide o melhor meio de estruturar este conhecimento (Genaro, 1986).

Estes sistemas estão sendo desenvolvidos para auxiliar os especialistas nas tarefas de planejamento, no diagnóstico de doenças, na localização de depósitos minerais, entre outras. Liao (2005) enfatiza que diferentes aplicações de sistemas especialistas ampliam os horizontes, tanto acadêmicos como os que envolvem tarefas que possam ser desenvolvidas pelo uso destes sistemas. Durkin (1994) apresenta como sugestão de escolha de um bom problema, a ser solucionado com o uso de sistema especialista, aquele que requer decisão humana para suas soluções.

De acordo com Eldrandaly, Eldin e Sui (2003) diversos sistemas especialistas buscam resolver problemas de seleção de local, que depende de julgamento e conhecimento humano, ou seja, requerem decisão humana para as suas soluções. Portanto, o desenvolvimento de sistema especialista para a seleção de um local auxilia o especialista nesta tomada de decisão, porquanto, como afirmam Harmon e King (1988), se o desenvolvimento da tarefa depender de conhecimentos subjetivos, mutáveis, simbólicos ou parcialmente opinativos, o problema poderá ser resolvido com o auxílio de um sistema especialista.

A partir dos conceitos estabelecidos, serão realizadas a seguir as atividades de descrição da organização pesquisada, implementação do SIG e do SE e análise dos resultados do Sistema Proposto.

\section{Delimitação e Execução da Pesquisa}

\section{Delineamento da pesquisa}

Esta pesquisa é de cunho qualitativo, tratando-se de estudo de caso que considera as agências do Banco HSBC em Curitiba, com avaliação transversal.

O desenvolvimento desta pesquisa foi realizado com as seguintes técnicas e instrumentos, explicitados a seguir.

Para a coleta de dados: pesquisa de campo para entrevista estruturada com objetivo de coletar os dados primários, análise de documentos e pesquisa no site http://www.hsbc.com.br.

. Para as proposições: projeto e implementação do sistema, com utilização de softwares específicos para geração de mapas.

- Para a análise: sistematização dos resultados e comparação dos resultados do sistema proposto com a metodologia tradicional adotada pelos usuários do HSBC.

\section{Organização pesquisada}

O HSBC Bank Brasil S/A - Banco Múltiplo está presente no Brasil em cerca de 550 municípios, que contam com mais de 1.700 agências e postos de atendimento. No município de Curitiba/PR totalizam 29 agências, 49 Postos de Atendimento Bancário (PAB) e 41 Postos de Atendimento Eletrônico (PAE), dados referentes ao mês de março de 2006. As análises de expansão, 
redução ou remanejamento da rede de produtos ou serviços competem aos departamentos de Rede de Agências, PAB's e PAYROLL e Administração de Imóveis. O departamento de Rede de Agências realiza os estudos de viabilidade de cada agência. Já o departamento de PAB's e PAYROLL realiza estudos de viabilidade dos postos de atendimento bancário. Ao departamento de Administração de Imóveis cabe a administração e viabilização de implantações e relocações de agências e PAB's. Por meio de serviços terceirizados às imobiliárias, são levantados os possíveis imóveis para implantação de uma nova agência bancária, considerando-se as agências existentes, as agências concorrentes, os pólos geradores de tráfego e arruamentos principais. Posteriormente, é analisada a melhor opção, com base em valores de aluguel, estrutura física e raio de ação, finalizando o processo com a concordância da Diretoria Executiva.

Segundo o Gerente de Imóveis - Corporate Real Estate do HSBC Curitiba/PR, o departamento de Administração de Imóveis não faz uso de Sistemas de Informações Geográficas ou sistema especialista. O departamento de Administração de Imóveis recebe mapas impressos das empresas que prestam assessoria nas tarefas de prospecção dos imóveis (imobiliárias), normalmente adquiridos em papelarias e bancas de jornal, ou mapas digitais em formato de arquivo, com extensão JPEG obtidos via internet, contendo o arruamento da região com a localização dos pontos pesquisados. No caso dos mapas impressos, os pontos são assinalados manualmente.

As decisões de localização são apoiadas em critérios muitas vezes opinativos, envolvendo uma série de medidas tomadas sem metodologia, tanto interna do departamento como pelas imobiliárias. Desenvolver o SIG integrado ao SE é uma necessidade, porque ajudará os envolvidos no processo a resolverem os problemas de forma mais rápida, visto que um maior número de informações estarão reunidas e sintetizadas. A localização geográfica de um ponto comercial em qualquer setor constitui recurso físico imprescindível; entretanto, a tarefa de selecionar a melhor localização é complexa, pois envolve variáveis não só espaciais como também simbólicas e, muitas vezes, opinativas.

\section{Desenvolvimento do sistema de informações geográficas}

Para a implementação do SIG a primeira etapa foi a adequação da base cartográfica digital do município de Curitiba/PR, que foi obtida do Instituto de Pesquisa e Planejamento Urbano de Curitiba (IPPUC), edição 2005. Os informes do banco de dados das agências bancárias, PAB's e PAE's foram definidos a partir das análises a serem efetuadas no SIG. Os endereços foram obtidos no Banco Central do Brasil (BC) referentes a janeiro de 2006. O departamento CSU - Processos Judiciais do HSBC forneceu os endereços das suas agências, PAB's e PAE's referentes a março de 2006, que foram comparados com a tabela fornecida pelo $\mathrm{BC}$ e atualizados. Os dados socioeconômicos foram obtidos no Instituto Brasileiro de Geografia e Estatística (IBGE) referentes ao ano 2000.

Foi efetuado o georreferenciamento das agências, PAB's e PAE's tanto do HSBC como da concorrência, totalizando aproximadamente 900 pontos, conforme Figura 1, para posterior visualização de forma combinada com os dados socioeconômicos, pólos geradores de tráfego, entre outros. No desenvolvimento do SIG foi utilizado o software ArcGIS 9.0 da empresa ESRI, licenciado no Departamento de Geomática da Universidade Federal do Paraná (UFPR). 


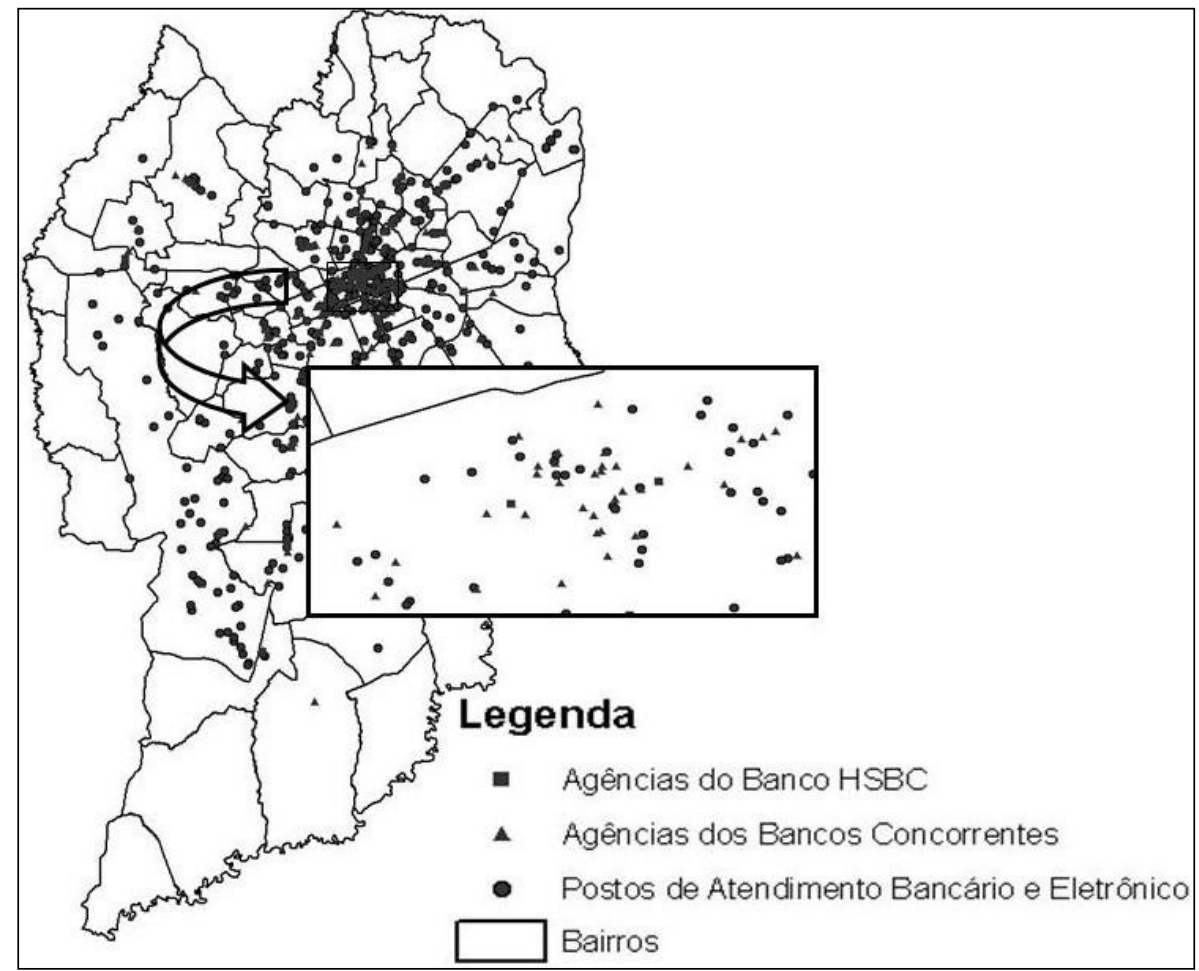

Figura 1: Agências do Banco HSBC e Bancos Concorrentes, PAB's e PAE's.

Fonte: Carnasciali, A. M. S. (2007). Integração de sistemas de informações geográficas e sistema especialista visando auxiliar a tomada de decisão locacional do setor bancário (p. 48). Dissertação de mestrado, Universidade Federal do Paraná, Curitiba, PR, Brasil.

Nas reuniões com os especialistas do DAI, foram determinadas as variáveis espaciais para as análises das regiões: renda, densidade demográfica, população, pólos geradores de tráfego e taxa de crescimento dos bairros. Como existem diferentes variáveis espaciais que contribuem para a escolha da localização mais adequada de uma nova agência bancária, os especialistas estabeleceram uma hierarquia, isto é, uma ordem de importância entre elas, de modo a identificar a contribuição relativa de cada uma. O limite das regiões foi definido pelo setor censitário, as variáveis espaciais receberam pesos dos especialistas e posteriormente foram combinadas, chegando-se a uma nota para a região (Tabela 2).

Tabela 2

Extrato da Tabela de Atributos dos Setores Censitários

\begin{tabular}{ccccccc}
\hline Setor & $\begin{array}{c}\text { Renda } \\
(\mathbf{R} \$)\end{array}$ & $\begin{array}{c}\text { Densidade } \\
\text { Demográfica } \\
\left(\mathbf{H a b} / \mathbf{K m}^{2}\right)\end{array}$ & $\begin{array}{c}\text { População } \\
(\mathbf{H a b})\end{array}$ & $\begin{array}{c}\text { Pólos } \\
\text { Geradores } \\
\text { de Tráfego } \\
\left(\mathbf{N}^{\mathbf{0}}\right)\end{array}$ & $\begin{array}{c}\text { Taxa de } \\
\text { Crescimento } \\
\text { dos Bairros } \\
(\% \text { ao ano })\end{array}$ & Nota \\
\hline $\mathrm{d} 410690205060313$ & 784,83 & 0,33 & 113 & 1 & 14,12 & 5,97 \\
$\mathrm{~d} 410690205020208$ & 472,32 & 0,36 & 77 & 6 & 1,81 & 6,30 \\
$\mathrm{~d} 410690205080012$ & 629,46 & 0,65 & 597 & 1 & 1,56 & 5,63 \\
$\mathrm{~d} 410690205070245$ & 363,28 & 0,96 & 702 & 7 & 1,06 & 6,67 \\
\hline
\end{tabular}

Nota. Fonte: Carnasciali, A. M. S. (2007). Integração de sistemas de informações geográficas e sistema especialista visando auxiliar a tomada de decisão locacional do setor bancário (p. 51). Dissertação de mestrado, Universidade Federal do Paraná, Curitiba, PR, Brasil. 
Foi estabelecido um intervalo de cinco classes para as regiões, o que possibilita identificar aquelas que receberam as melhores pontuações (Figura 2). As análises referentes à seleção da região foram efetuadas sobre a base cartográfica digital do Município de Curitiba/PR; consideraram-se, além dos setores censitários classificados de acordo com o intervalo de notas, as agências do HSBC e dos bancos concorrentes, hipermercados, as faculdades, escolas e os arruamentos principais.

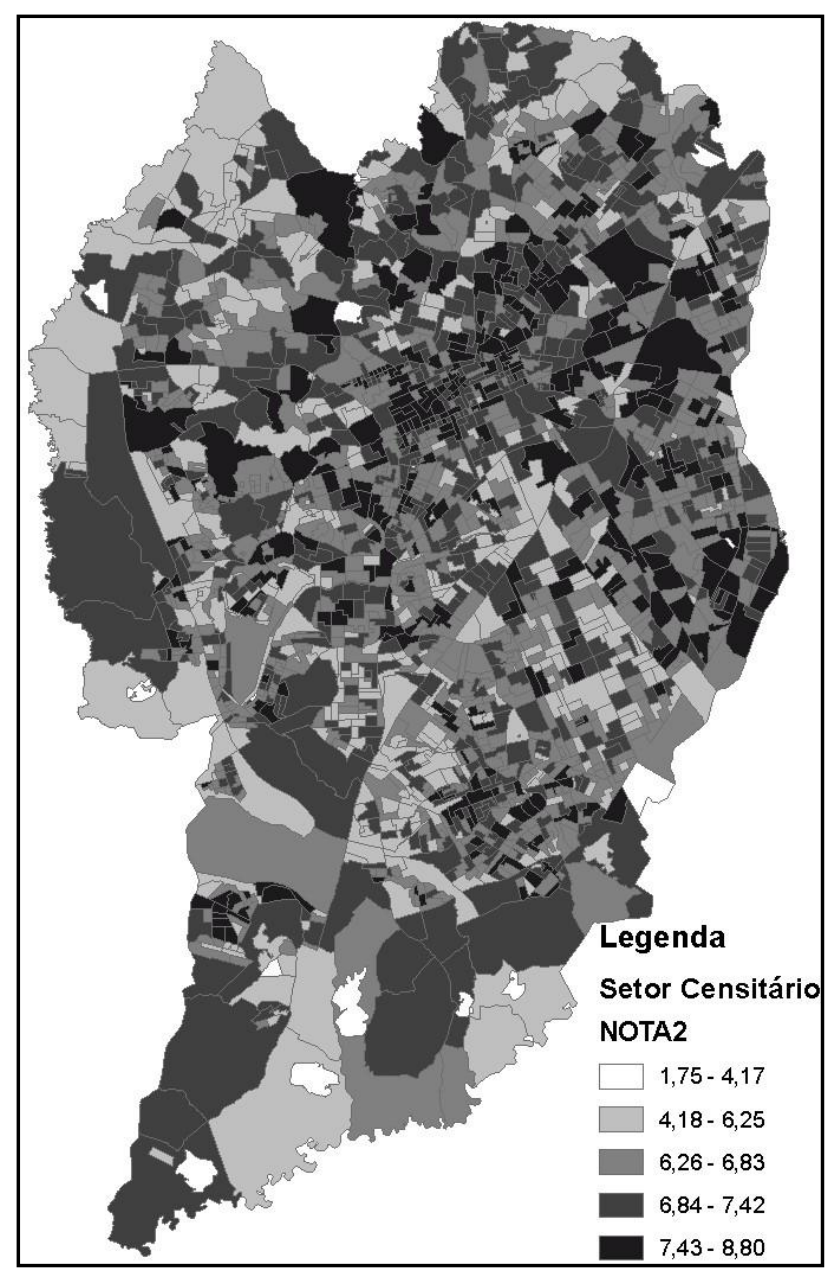

Figura 2. Setores Censitários Classificados Segundo as Notas.

Fonte: Carnasciali, A. M. S. (2007). Integração de sistemas de informações geográficas e sistema especialista visando auxiliar a tomada de decisão locacional do setor bancário (p. 52). Dissertação de mestrado, Universidade Federal do Paraná, Curitiba, PR, Brasil.

Foram analisadas diversas possibilidades para escolha da região a ser estudada e foi escolhido o bairro Sítio Cercado, por se tratar de bairro que, segundo dados do IBGE, apresentou crescimento de $3,56 \%$ ao ano, apresenta população de 102.410 habitantes, densidade demográfica de $92,07 \mathrm{hab} / \mathrm{km}^{2}$, além de escolas estaduais e municipais, bibliotecas, postos de saúde e supermercados. Assim, a região da Rua Izaac Ferreira da Cruz, foi analisada devido à instalação de apenas um banco (Banco Itaú S/A) e por ter as melhores pontuações.

\section{Desenvolvimento do sistema especialista}

Paralelamente ao desenvolvimento do SIG, foi realizada a etapa de aquisição do conhecimento, que consistiu em estudos de livros sobre marketing, economia regional e geomarketing, bem como de artigos relacionados à tomada de decisões que envolvem a melhor localização de um ponto. O objetivo desses estudos foi adquirir familiarização com os termos principais da especialidade. 
Em janeiro de 2006, foram realizadas reuniões com os especialistas do DAI, a fim de reunir informações de como é decidida a melhor localização para a abertura de nova agência bancária e de quais foram os procedimentos por eles adotados, buscando entender suas linhas de raciocínio. As reuniões foram realizadas a pedido da Sra. Ana Maria dos Santos Carnasciali, Engenheira Cartógrafa e pesquisadora com o Sr. Reginaldo Mendes, Gerente de Administração de Imóveis; Sr. Fernando Klupper, Analista de Contratos; Sr. Marcelo Luis Casagrande, Analista de Patrimônio; e Sra. Sandra Mendes da Rocha, Analista de Legislação. Durante as reuniões, foi solicitado aos especialistas que descrevessem seus procedimentos de trabalho, procurando enfatizar as variáveis consideradas indispensáveis em suas análises. A partir destas reuniões foram determinadas as variáveis simbólicas relevantes para as análises dos pontos: região, finalidade, área, pavimentos, valor de mercado, localização do imóvel/quadra, visibilidade, localização do imóvel/via, sistema viário, pedestre, entorno, transporte urbano, acesso da rua/imóvel, acesso deficiente físico/mobilidade reduzida, iluminação/ventilação, sanitários, estacionamento, acesso ao estacionamento, uso do estacionamento, segunda saída de incêndio e publicidade. Como existem diferentes variáveis simbólicas que contribuem para a escolha da localização mais adequada de uma nova agência bancária, os especialistas estabeleceram uma hierarquia, isto é, uma ordem de importância entre elas de modo a identificar a contribuição relativa de cada uma (Tabela 3).

Tabela 3

\section{Hierarquia das Variáveis Simbólicas}

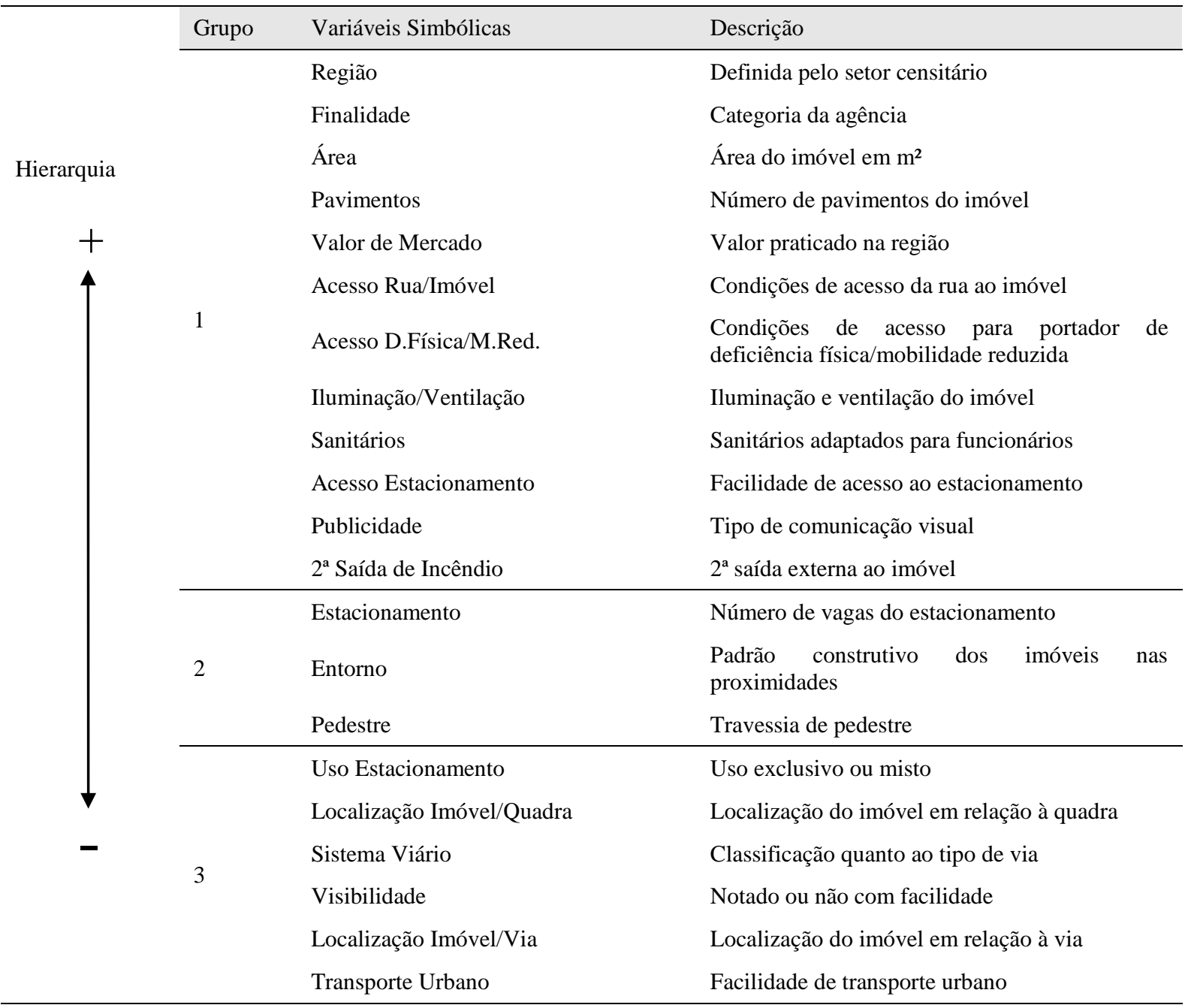

Nota. Fonte: Carnasciali, A. M. S. (2007). Integração de sistemas de informações geográficas e sistema especialista visando auxiliar a tomada de decisão locacional do setor bancário (p. 60). Dissertação de mestrado, Universidade Federal do Paraná, Curitiba, PR, Brasil. 
Para o desenvolvimento do SE optou-se pelo Shell Expert SINTA 1.1 do grupo SINTA (Sistemas Inteligentes Aplicados) da Universidade Federal do Ceará. Das diversas representações que existem para a criação de bases de conhecimento, as regras de produção são as utilizadas pelo Expert SINTA. Para o desenvolvimento do SE foram elaboradas 178 regras, totalizando 22 perguntas formuladas pelo sistema dos especialistas. Um exemplo é apresentado na Figura 3.

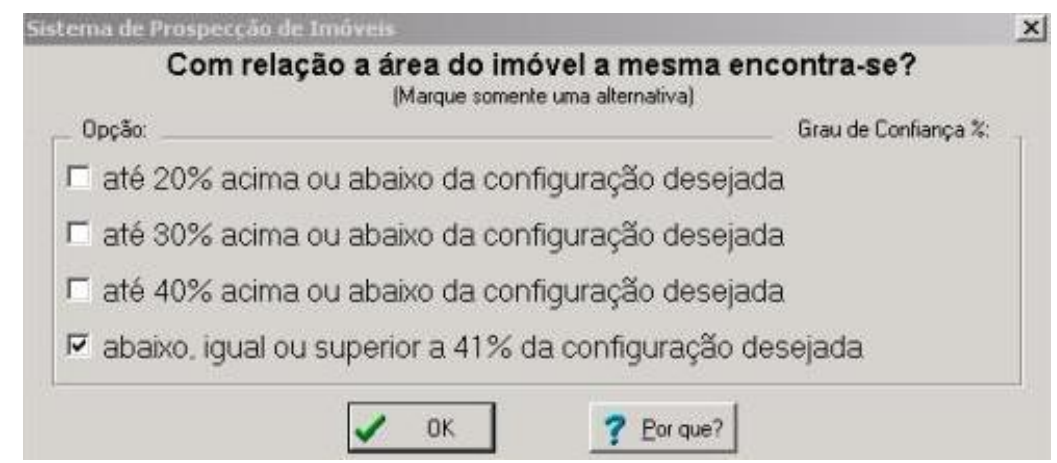

Figura 3. Tela de Pergunta ao Especialista.

Fonte: Carnasciali, A. M. S. (2007). Integração de sistemas de informações geográficas e sistema especialista visando auxiliar a tomada de decisão locacional do setor bancário (p. 65). Dissertação de mestrado, Universidade Federal do Paraná, Curitiba, PR, Brasil.

Também foram elaborados menus de ajuda, com explicações sobre a pergunta que está sendo efetuada. No desenvolvimento dos menus de ajuda utilizou-se o software HelpScribble 7.6.1.

\section{Integração dos sistemas}

Para a integração dos sistemas foi desenvolvida uma interface, com a linguagem de programação Visual Basic 6.0. O sistema desenvolvido neste trabalho, que consistiu na integração de um SIG e um SE, foi denominado Sistema de Prospecção de Imóveis para o Setor Bancário (SPI) (Figura 4).

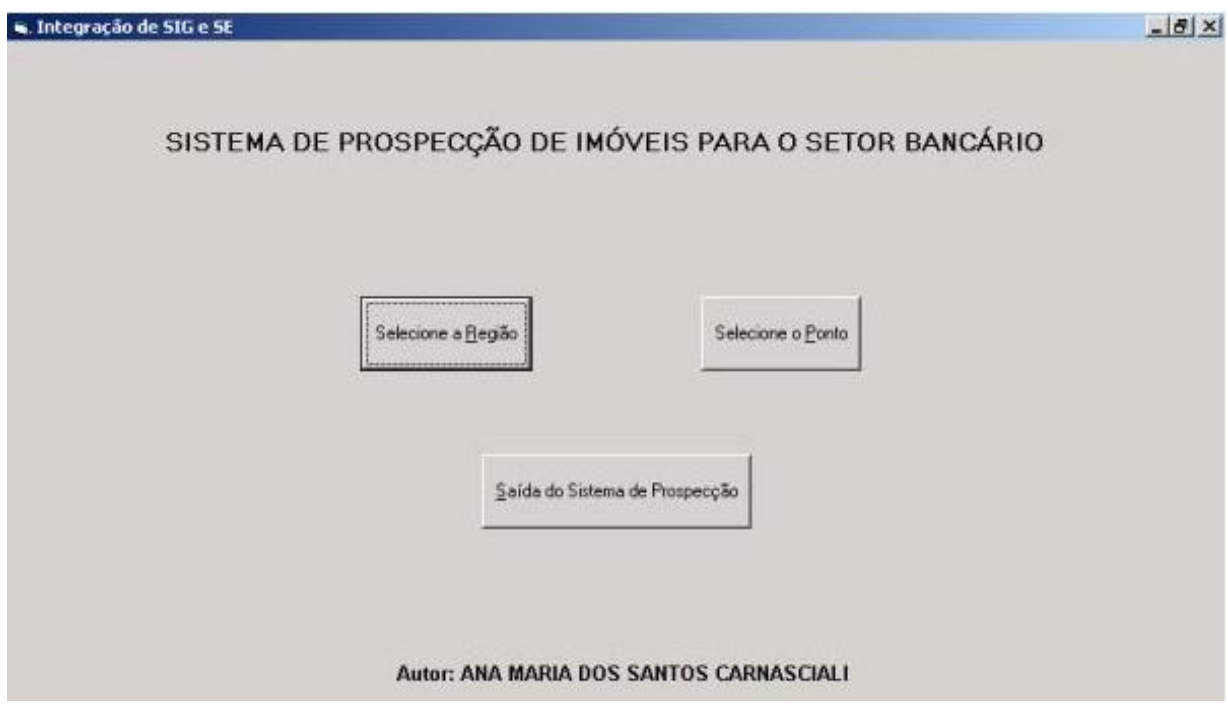

Figura 4. Sistema de Prospecção de Imóveis para o Setor Bancário (SPI)

Fonte: Carnasciali, A. M. S. (2007). Integração de sistemas de informações geográficas e sistema especialista visando auxiliar a tomada de decisão locacional do setor bancário (p. 66). Dissertação de mestrado, Universidade Federal do Paraná, Curitiba, PR, Brasil.

Inicialmente, o usuário, no caso o especialista do HSBC, é questionado no SPI se existe uma região (bairro ou conjunto de bairros) previamente definida. Em caso negativo, é instruído para 
selecioná-la no SIG. Com a região definida, parte-se para a definição do ponto; esta etapa exige que seja realizada a prospecção dos imóveis na região de interesse.

\section{Prospecção dos imóveis}

Conforme descrito no item Desenvolvimento do Sistema de Informações Geográficas com o auxílio do SIG chegou-se à conclusão de que a melhor região para abertura de nova agência seria o Bairro do Sitio Cercado, próximo à rua Isaac Ferreira da Cruz. O trabalho de prospecção dos imóveis nesta região foi delegado para uma imobiliária. Entretanto, devido às dificuldades encontradas pela imobiliária, e em concordância com os especialistas do HSBC, efetuou-se pessoalmente a prospecção dos imóveis, de modo a atender à configuração necessária para implantação de agência padrão. Foram encontrados para locação quatro imóveis. Foi solicitado às imobiliárias uma visita deles para levantar informações indispensáveis à avaliação de viabilidade de uso.

A pedido do DAI, as imobiliárias efetuam o preenchimento de uma ficha denominada Oferta de Imóveis (OI). A ficha contém informações do ofertante (nome, telefone/fax, e-mail), do imóvel (endereço, área do terreno, área edificada, matrícula), identificação/diagnóstico do imóvel (indicação fiscal, zoneamento urbano, entre outros), informações geográficas e socioeconômicas da região do imóvel, condições da oferta, descrição do imóvel (número de pavimentos, vagas de estacionamento, entre outros). Com base nas informações assinaladas, é feita uma pré-análise do imóvel. Caso haja interesse, os especialistas das áreas de Legalização, Manutenção, Fire \& Safety e Negociação, são acionados para emitirem seus pareceres.

Com o objetivo de proceder às análises dos imóveis, comparando-se o processo atualmente usado pelo departamento com o sistema proposto, efetuou-se o preenchimento das fichas OI para os imóveis prospectados. Em seguida, solicitou-se que os especialistas das áreas de Contratos (especialista 1), Legislação Imobiliária (especialista 2) e Patrimônio (especialista 3) os avaliassem e emitissem pareceres sobre os imóveis prospectados pela análise dos elementos constantes nas fichas OI. Todos deveriam descrever os fatores que influenciaram e/ou auxiliaram no julgamento da viabilidade do imóvel; no término da avaliação, deveria ser estabelecida uma hierarquia entre as quatro opções. Para tanto foi elaborada uma ficha denominada Avaliação Efetuada pelos Especialistas dos Imóveis Prospectados (AEIP). Posteriormente, procedeu-se à avaliação por meio da utilização do Sistema de Prospecção de Imóveis para o Setor Bancário (SPI) desenvolvido neste trabalho.

\section{Análise dos resultados do SPI}

A partir das fichas AEIP foram analisadas as variáveis simbólicas consideradas pelos especialistas: localização do imóvel/quadra, área, acesso deficiente físico/mobilidade reduzida, valor de mercado, pavimentos, fachada, entorno, visibilidade, publicidade, estacionamento, sanitários, acesso estacionamento, iluminação/ventilação, transporte urbano e segunda saída de incêndio. Desta análise foi possível efetuar as seguintes considerações abaixo.

1. Apenas três variáveis (área, acesso para portador de deficiência física ou mobilidade reduzida e valor de mercado) foram consideradas pelos três especialistas, mesmo que algumas variáveis tenham sido apontadas para apenas um imóvel. As variáveis localização imóvel/quadra, pavimentos, publicidade, estacionamento e transporte urbano foram consideradas por dois especialistas, mesmo que algumas variáveis tenham sido apontadas para apenas um imóvel. A variável fachada foi considerada apenas pelo especialista 1. As variáveis entorno, visibilidade, sanitários, acesso estacionamento, iluminação/ventilação foram consideradas apenas pelo especialista 2. A variável segunda saída de incêndio foi considerada apenas pelo especialista 3 , mesmo que tenha sido apontada por eles para apenas um imóvel.

2. Nenhum especialista considerou todas as variáveis simbólicas que compõem o sistema proposto durante as avaliações dos quatro imóveis, sendo importante destacar que elas foram indicadas durante as entrevistas pelos especialistas como indispensáveis para as análises. Como ilustração da 
importância de todas as varáveis nas análises, pode-se citar que a variável acesso rua/imóvel pode indicar a necessidade de obras de adequação, o que certamente implicará aumento de custos, se comparado com outro imóvel que esteja dentro das conformidades esperadas. Este fato configura que os especialistas não consideram todas as variáveis simbólicas ou por não as terem como foco nas funções que desempenham ou até mesmo por esquecimento.

3. Todas as variáveis foram ponderadas qualitativamente pelos três especialistas, fato evidenciado pelo uso de expressões subjetivas e adjetivos, como estes: desejável, acima do desejável, muito acima do desejável, abaixo do desejável, excelente, bom, ruim, melhor, insuficiente, compatível, acima da necessidade, abaixo da necessidade, muito abaixo, muito inferior, alto, adequado, entre outras. A variável fachada foi analisada pelo especialista 1; mas, no desenvolvimento do sistema proposto, ela não foi considerada relevante pelos especialistas pelo fato de que, independentemente do imóvel o banco sempre efetuará a adequação dela para manter a padronização de todas as agências.

Procedeu-se à avaliação por meio da utilização do Sistema de Prospecção de Imóveis para o Setor Bancário (SPI), desenvolvido neste trabalho. Para tanto, foram respondidas para os quatro imóveis 22 perguntas realizadas pelo sistema, com base nas informações levantadas in loco. O sistema apresenta, no término da consulta de cada imóvel, uma nota, que permite identificar aquele que obteve a maior pontuação, auxiliando o especialista na seleção do melhor ponto. Ressalta-se que com utilização dele todas as variáveis simbólicas são analisadas. Foi efetuada uma tabulação da hierarquia dos imóveis com base nos resultados apresentados pelo sistema proposto e pelos especialistas, conforme Tabela 4.

Tabela 4

Hierarquia dos Imóveis Prospectados pelo SPI e Especialistas do HSBC

\begin{tabular}{ccccc}
\hline \multicolumn{1}{c}{ Hierarquia dos Imóveis Prospectados } \\
\hline \multirow{2}{*}{ Imóvel } & SPI & \multicolumn{3}{c}{ Especialista } \\
\cline { 3 - 5 } & & 1 & 2 & 3 \\
\hline 1 & $2^{\mathrm{a}}$ & $2^{\mathrm{a}}$ & $1^{\mathrm{a}}$ & $3^{\mathrm{a}}$ \\
2 & $3^{\mathrm{a}}$ & $3^{\mathrm{a}}$ & $2^{\mathrm{a}}$ & $2^{\mathrm{a}}$ \\
3 & $1^{\mathrm{a}}$ & $1^{\mathrm{a}}$ & $2^{\mathrm{a}}$ & $1^{\mathrm{a}}$ \\
4 & Desconsiderar & Descartar & $2^{\mathrm{a}}$ & Inviabilizar \\
\hline
\end{tabular}

Nota. Fonte: Carnasciali, A. M. S. (2007). Integração de sistemas de informações geográficas e sistema especialista visando auxiliar a tomada de decisão locacional do setor bancário (p. 80). Dissertação de mestrado, Universidade Federal do Paraná, Curitiba, PR, Brasil.

Analisando-se a ficha AEIP e a Tabela 3, é possível fazer as seguintes considerações.

1. O especialista 1 considerou, numa primeira avaliação, os imóveis 1 e 3 empatados. Como critério de desempate considerou o menor investimento para adaptações, no caso do imóvel 3 (Térreo). Mesmo que inicialmente o especialista tenha chegado a um empate, suas opções coincidiram com as apontadas pelo sistema. Tratando-se do especialista diretamente responsável pelas prospecções dos imóveis do HSBC, com 10 anos de experiência na função, serve como parâmetro positivo para avaliar o desempenho do sistema proposto.

2. As opções do especialista 2 não coincidem com as apontadas pelo sistema nem pelas apontadas pelos outros dois especialistas. Curiosamente foi o que mais variáveis considerou nas análises. Apontou que a metragem do imóvel 4 estava abaixo do necessário, mas não descreve que ele deve ser desconsiderado. Tratando-se de um especialista que atua na área de Legislação, com 5 anos de experiência na função, percebe-se uma inclinação para essa área durante as análises, quando se 
refere aos imóveis 1 e 3 'necessidade de iluminação artificial e ventilação mecânica em todos os cômodos (não adequado à Legislação), não há janelas'. Após a entrega das fichas os especialistas discutiram se esse fator poderia ser restritivo e chegou-se à conclusão de que para Curitiba é possível implantar tanto a ventilação mecânica, quanto a iluminação artificial; portanto os imóveis apontados como $2^{\mathrm{a}}$ opção poderiam ter sido hierarquizados.

3. O especialista 3 considerou o imóvel 3 como $1^{\mathrm{a}}$ opção, coincidindo com o sistema. Com relação à $2^{\mathrm{a}}$ e a $3^{\mathrm{a}}$ opção, o especialista argumenta para o imóvel 1 'imóvel com ponto desejável, porém com dois pavimentos'; e para o imóvel 2 'imóvel com área acima do desejável... verificar a possibilidade de locação de metade do imóvel'. Percebe-se, portanto, que a $2^{\mathrm{a}}$ opção foi tomada com base em suposições, partindo-se da possibilidade de desmembramento do imóvel, considerando o $1^{\mathrm{o}}$ imóvel como $3^{\mathrm{a}}$ opção, devido aos 2 pavimentos. Ao compararmos suas opções com as apresentadas pelo sistema, elas são divergentes. Entretanto, é importante destacar que o sistema não trabalha com o condicionante se, seus resultados são baseados em dados concretos e não em conjeturas.

As análises acima descritas formam o arcabouço para a realização das análises dos imóveis em termos de vantagem competitiva, conforme descrito a seguir.

\section{Análise dos Imóveis Prospectados em Termos de Vantagem Competitiva}

Para a análise dos imóveis prospectados em termos de vantagem competitiva, foram separadas as variáveis simbólicas, considerando as políticas internas do banco e seus clientes.

$\mathrm{Na}$ Tabela 5 é apresentado um resumo dos recursos avaliados para as políticas internas do banco. Com base nele, foi elaborada a Tabela 6 referente às análises dos imóveis prospectados para as políticas internas do banco, em termos de vantagem competitiva.

Tabela 5

Resumo dos Recursos Avaliados para as Políticas Internas do Banco

\begin{tabular}{|c|c|c|c|c|}
\hline \multirow{2}{*}{ Variáveis Simbólicas } & \multicolumn{4}{|c|}{ Imóvel } \\
\hline & 1 & 2 & 3 & 4 \\
\hline Região & Sítio Cercado & Sítio Cercado & Sítio Cercado & Sítio Cercado \\
\hline Finalidade & Ag. Standard & Ag. Standard & Ag. Standard & Ag. Standard \\
\hline Área $\left(\mathrm{m}^{\mathrm{a}}\right)$ & 600 & 768 & 468 & 180 \\
\hline Pavimentos & 2 Pav. e 1 Subsolo & Térreo & Térreo & Térreo \\
\hline Valor de Mercado & No valor & No valor & No valor & No valor \\
\hline $\begin{array}{l}\text { Iluminação/ } \\
\text { Ventilação }\end{array}$ & $\begin{array}{l}\text { Não exigirá adequação } \\
\text { e implantação }\end{array}$ & Implantar & Adequar & Implantar \\
\hline Sanitários & Sim & Sim & Sim & Não \\
\hline Publicidade & $\begin{array}{l}\text { Perpendicular/ } \\
\text { Fachada/Totem }\end{array}$ & $\begin{array}{l}\text { Perpendicular/ } \\
\text { Fachada/Totem }\end{array}$ & $\begin{array}{l}\text { Perpendicular/ } \\
\text { Fachada }\end{array}$ & Fachada \\
\hline 2ª Saída de Incêndio & $\begin{array}{l}\text { Não existe, mas é } \\
\text { possível adaptar }\end{array}$ & $\begin{array}{l}\text { Não existe, mas é } \\
\text { possível daptar }\end{array}$ & Existe & $\begin{array}{l}\text { Não existe e não } \\
\text { é possível adaptar }\end{array}$ \\
\hline Entorno & Semelhante & Semelhante & Semelhante & Semelhante \\
\hline Uso Estacionamento & Uso exclusivo & Uso misto & Uso misto & Uso misto \\
\hline Loc. Imóvel/Quadra & Esquina & Esquina & Meio quarteirão & Meio quarteirão \\
\hline
\end{tabular}

Nota. Fonte: elaborado pelos autores a partir dos dados coletados. 
Tabela 6

\section{Análise para as Políticas Internas do Banco em termos de Vantagem Competitiva}

\begin{tabular}{|c|c|c|c|c|c|c|c|}
\hline Recurso & Variáveis Simbólicas & $\begin{array}{c}\text { A empresa } \\
\text { possui }\end{array}$ & Valioso & Raro & $\begin{array}{l}\text { Difícill } \\
\text { mitar }\end{array}$ & $\begin{array}{c}\text { Difícil } \\
\text { Substituir }\end{array}$ & $\begin{array}{l}\text { ImplicaçõesE } \\
\text { stratégicas }\end{array}$ \\
\hline \multirow{12}{*}{$\begin{array}{c}\text { Imóvel } \\
1\end{array}$} & Região & Sim & Sim & Não & - & - & PCT \\
\hline & Finalidade & Sim & Sim & Não & - & - & PCT \\
\hline & Área $\left(m^{a}\right)$ & Sim & Não & - & - & - & DC \\
\hline & Pavimentos & Sim & Não & - & - & - & DC \\
\hline & Valor de Mercado & Sim & Sim & Não & - & - & PCT \\
\hline & Iluminação/Ventilação & Sim & Sim & Sim & Sim & Não & $\mathrm{PC}$ \\
\hline & Sanitários & Sim & Sim & Sim & - & - & VCT \\
\hline & Publicidade & Sim & Sim & Sim & Não & - & VCT \\
\hline & $2^{a}$ Saída de Incêndio & Sim & Sim & Não & - & - & PCT \\
\hline & Entorno & Sim & Sim & Não & - & - & PCT \\
\hline & Uso Estacionamento & Sim & Sim & Não & - & - & PCT \\
\hline & Loc. Imóvel/Quadra & Sim & Sim & Sim & Sim & Não & $\mathrm{PC}$ \\
\hline \multirow{12}{*}{$\begin{array}{c}\text { Imóvel } \\
2\end{array}$} & Região & Sim & Sim & Não & - & - & PCT \\
\hline & Finalidade & Sim & Sim & Não & - & - & PCT \\
\hline & Área $\left(m^{a}\right)$ & Sim & Não & - & - & - & DC \\
\hline & Pavimentos & Sim & Sim & Não & - & - & PCT \\
\hline & Valor de Mercado & Sim & Sim & Não & - & - & PCT \\
\hline & Iluminação/Ventilação & Não & - & - & - & - & $\mathrm{DC}$ \\
\hline & Sanitários & Sim & Sim & Sim & - & - & VCT \\
\hline & Publicidade & Sim & Sim & Sim & Não & - & VCT \\
\hline & $2^{\text {a }}$ Saída de Incêndio & Sim & Sim & $\operatorname{Sim}$ & Sim & Não & $\mathrm{PC}$ \\
\hline & Entorno & Sim & Sim & Não & - & - & PCT \\
\hline & Uso Estacionamento & Sim & Não & - & - & - & DC \\
\hline & Loc. Imóvel/Quadra & Sim & Sim & Sim & Sim & Não & PC \\
\hline \multirow{12}{*}{$\begin{array}{c}\text { Imóvel } \\
3\end{array}$} & Região & Sim & Sim & Não & - & - & PCT \\
\hline & Finalidade & Sim & Sim & Não & - & - & PCT \\
\hline & Área $\left(m^{a}\right)$ & Sim & Sim & Sim & Sim & Sim & VCS \\
\hline & Pavimentos & Sim & Sim & Não & - & - & PCT \\
\hline & Valor de Mercado & Sim & Sim & Não & - & - & PCT \\
\hline & Iluminação/Ventilação & Sim & Sim & - & - & - & PCT \\
\hline & Sanitários & Sim & Sim & Sim & - & - & VCT \\
\hline & Publicidade & Sim & Sim & Não & - & - & PCT \\
\hline & $2^{\text {a }}$ Saída de Incêndio & Sim & Sim & Sim & Sim & Sim & VCS \\
\hline & Entorno & Sim & Sim & Não & - & - & PCT \\
\hline & Uso Estacionamento & Sim & Não & - & - & - & DC \\
\hline & Loc. Imóvel/Quadra & Sim & Sim & Não & - & - & PCT \\
\hline
\end{tabular}


Tabela 6 (continuação)

\begin{tabular}{|c|c|c|c|c|c|c|c|}
\hline Recurso & Variáveis Simbólicas & $\begin{array}{c}\text { A empresa } \\
\text { possui }\end{array}$ & Valioso & Raro & $\begin{array}{l}\text { Difícil } \\
\text { Imitar }\end{array}$ & $\begin{array}{c}\text { Difícil } \\
\text { Substituir }\end{array}$ & $\begin{array}{l}\text { Implicações } \\
\text { Estratégicas }\end{array}$ \\
\hline \multirow{12}{*}{$\begin{array}{c}\text { Imóvel } \\
4\end{array}$} & Região & Sim & Sim & Não & - & - & PCT \\
\hline & Finalidade & Sim & Sim & Não & - & - & PCT \\
\hline & Área $\left(m^{a}\right)$ & Sim & Não & - & - & - & DC \\
\hline & Pavimentos & Sim & Sim & Não & - & - & PCT \\
\hline & Valor de Mercado & Sim & Sim & Não & - & - & PCT \\
\hline & Iluminação/Ventilação & Não & - & - & - & - & DC \\
\hline & Sanitários & Não & - & - & - & - & DC \\
\hline & Publicidade & Sim & Sim & Não & - & - & PCT \\
\hline & 2a Saída de Incêndio & Não & - & - & - & - & DC \\
\hline & Entorno & Sim & Sim & Não & - & - & PCT \\
\hline & Uso Estacionamento & Sim & Não & - & - & - & DC \\
\hline & Loc. Imóvel/Quadra & Sim & Sim & Não & - & - & PCT \\
\hline
\end{tabular}

Nota. Fonte: Elaborado pelos autores a partir dos dados coletados.

\section{Análises para as políticas internas do banco}

Os quatro imóveis apresentaram paridade competitiva temporária para a região, pois estão localizados no mesmo bairro, o qual possui também agências de bancos concorrentes. A finalidade corresponde a abertura de agência padrão. Essa categoria abrange maior número de clientes, diferente da Premier, cujos clientes são selecionados de acordo com o maior poder aquisitivo, quando comparado com a anterior. Trata-se de variável valiosa, mas não rara, pois os demais bancos também fazem uso de categorização de agências de acordo com o perfil dos clientes, implicando, portanto, paridade competitiva temporária. A área varia em torno de $500 \mathrm{~m}^{2}$ para agência padrão e $700 \mathrm{~m}^{2}$ para agência padrão com Premier. As áreas dos imóveis 1 e 2 são superiores às necessidades do banco, enquanto a área do imóvel 3 é inferior, constituindo-se em desvantagem competitiva. Em contrapartida, o imóvel 4 apresenta vantagem competitiva sustentável, pois nessa localização não existem imóveis disponíveis com essa característica. De acordo com o número de pavimentos, o imóvel 1 apresenta desvantagem competitiva, pois ele possui dois pavimentos, sendo um excedente. Os demais imóveis apresentam paridade competitiva temporária, pois houve maior facilidade em localizar imóveis com o tipo de pavimento térreo. Os 4 imóveis, para a variável valor de mercado, apresentaram paridade competitiva temporária, pois o valor praticado de aluguel correspondia ao valor de mercado, não sendo raro, pois as agências concorrentes também buscam imóveis disponíveis que estejam dentro dos valores praticados na região. $\mathrm{O}$ imóvel 1 com respeito à variável iluminação/ventilação apresenta paridade competitiva, uma vez que ele pode ser utilizado sem necessidade de adequação/implantação. Nenhum outro imóvel disponível apresentou essas características; lembre-se que se trata de imóveis prospectados e não edificados pelo banco. O imóvel 3 apresenta paridade competitiva temporária, necessitando adequações. Já os imóveis 2 e 4 apresentam desvantagem competitiva, pois eles requerem implantação de iluminação/ventilação, ou seja, serão necessárias obras. Os imóveis 1, 2 e 3 para a variável sanitário, apresentam vantagem competitiva temporária, pois eles são separados por sexo, enquanto o imóvel 4 necessita de obras visando à construção de banheiros femininos e masculinos. Os imóveis 1 e 2 com relação à variável publicidade, apresentam vantagem competitiva temporária, pois imóveis que possibilitem a implantação dos três tipos de publicidade são raros, mas facilmente imitáveis; bancos concorrentes fazem uso dessas mesmas publicidades. Os imóveis 3 e 4 apresentam paridade competitiva temporária, pois os alvarás para esse tipo de publicidade são mais fáceis de conseguir. O imóvel 3 apresenta vantagem competitiva sustentável para a variável segunda saída de incêndio, uma vez que prospectar imóveis 
com segunda saída externa a ele é difícil de ser imitado pelos bancos concorrentes e ainda, nesse caso, não necessita de adequações. O imóvel 1 e 2 apresentam paridade competitiva temporária, pois requerem adaptações, enquanto o imóvel 4 apresenta desvantagem competitiva, pois não existe a segunda saída e não é possível adaptar. As agências localizadas nas proximidades necessitariam de obras para implantação, ou até mesmo tais obras não seriam possíveis, devido aos seus confrontantes. Os 4 imóveis apresentam paridade competitiva temporária para a variável entorno, pois o padrão construtivo dos imóveis nas proximidades é semelhante. O imóvel 1 apresenta paridade competitiva temporária, pois outras agências nas proximidades possuem estacionamento exclusivo. Já os demais imóveis apresentam desvantagem competitiva, pois os bancos concorrentes também recorrem a estacionamentos terceirizados, não próprios. Os imóveis 1 e 2 apresentam paridade competitiva para a variável localização do imóvel/quadra, pois nenhuma agência concorrente se localiza em esquina. Os imóveis 3 e 4 apresentam paridade competitiva temporária, pois agências concorrentes nas proximidades também estão localizadas no meio do quarteirão.

Na Tabela 7 é apresentado um resumo dos recursos avaliados para os clientes do banco. Com base nele, foi elaborada a Tabela 8 referente às análises dos imóveis prospectados para os clientes do banco em termos de vantagem competitiva.

Tabela 7

\section{Resumo dos Recursos Avaliados para os Clientes do Banco}

\begin{tabular}{|c|c|c|c|c|}
\hline \multirow{2}{*}{$\begin{array}{c}\text { Variáveis } \\
\text { Simbólicas }\end{array}$} & \multicolumn{4}{|c|}{ Imóvel } \\
\hline & $\mathbf{1}$ & 2 & 3 & 4 \\
\hline Acesso Rua/Imóvel & Escada/Degrau & Degrau & Degrau & Degrau \\
\hline $\begin{array}{c}\text { Aces. D.Física/ } \\
\text { M. Red. }\end{array}$ & Implantar elevador & $\begin{array}{l}\text { Adequar acesso } \\
\text { existente }\end{array}$ & $\begin{array}{c}\text { Adequar acesso } \\
\text { existente }\end{array}$ & $\begin{array}{c}\text { Adequar acesso } \\
\text { existente }\end{array}$ \\
\hline Aces. Estacionam. & No mesmo imóvel & No mesmo imóvel & No mesmo imóvel & Em outro imóvel \\
\hline Estacionamento & $\begin{array}{l}\text { Próprio com } \mathrm{n}^{\circ} \text { de } \\
\text { vagas suficientes }\end{array}$ & Terceirizado & Terceirizado & Terceirizado \\
\hline Pedestre & $\begin{array}{l}\text { Travessia distante } \\
\text { com semáforo }\end{array}$ & $\begin{array}{l}\text { Travessia próxima } \\
\text { com semáforo }\end{array}$ & $\begin{array}{l}\text { Travessia distante } \\
\text { com semáforo }\end{array}$ & $\begin{array}{c}\text { Travessia próxima } \\
\text { com semáforo }\end{array}$ \\
\hline Sistema Viário & Coletora & Coletora & Coletora & Coletora \\
\hline Visibilidade & $\begin{array}{l}\text { Notado com } \\
\text { facilidade }\end{array}$ & $\begin{array}{l}\text { Notado com } \\
\text { facilidade }\end{array}$ & $\begin{array}{l}\text { Não é notado } \\
\text { com facilidade }\end{array}$ & $\begin{array}{l}\text { Não é notado } \\
\text { com facilidade }\end{array}$ \\
\hline Loc. Imóvel/Via & Mesmo sentido & Mesmo sentido & Mesmo sentido & Mesmo sentido \\
\hline Transporte Urbano & Ponto de ônibus & Terminal & Terminal & Terminal \\
\hline
\end{tabular}

Nota. Fonte: elaborado pelos autores a partir dos dados coletados. 
Tabela 8

\section{Análise dos Recursos para os Clientes do Banco em termos de Vantagem Competitiva}

\begin{tabular}{|c|c|c|c|c|c|c|c|}
\hline & \multirow{2}{*}{ Variáveis Simbólicas } & \multicolumn{6}{|c|}{ O recurso é: } \\
\hline Recurso & & $\begin{array}{l}\text { Possuído } \\
\text { pela } \\
\text { Empresa }\end{array}$ & Valioso & Raro & $\begin{array}{l}\text { Difícil } \\
\text { de ser } \\
\text { imitado }\end{array}$ & $\begin{array}{c}\text { Difícil de } \\
\text { ser } \\
\text { substituído }\end{array}$ & $\begin{array}{l}\text { Implicações } \\
\text { Estratégicas }\end{array}$ \\
\hline \multirow{9}{*}{$\begin{array}{c}\text { Imóvel } \\
1\end{array}$} & Acesso Rua/Imóvel & Sim & Não & - & - & - & $\mathrm{DC}$ \\
\hline & $\begin{array}{c}\text { Aces.D.Física/ M. } \\
\text { Red. }\end{array}$ & Não & - & - & - & - & $\mathrm{DC}$ \\
\hline & $\begin{array}{c}\text { Aces. } \\
\text { Estacionamento }\end{array}$ & Sim & Sim & Não & - & - & PCT \\
\hline & Estacionamento & Sim & Sim & Sim & Sim & Não & $\mathrm{PC}$ \\
\hline & Pedestre & Sim & Sim & Não & - & - & PCT \\
\hline & Sistema Viário & Sim & Não & - & - & - & $\mathrm{DC}$ \\
\hline & Visibilidade & Sim & Sim & Não & - & - & PCT \\
\hline & Loc. Imóvel/Via & Sim & Sim & Não & - & - & PCT \\
\hline & Transporte Urbano & Sim & Sim & Não & - & - & PCT \\
\hline \multirow{9}{*}{$\begin{array}{c}\text { Imóvel } \\
2\end{array}$} & Acesso Rua/Imóvel & Sim & Não & - & - & - & DC \\
\hline & $\begin{array}{l}\text { Aces. D.Física/M. } \\
\text { Red. }\end{array}$ & Não & - & - & - & - & DC \\
\hline & $\begin{array}{c}\text { Aces. } \\
\text { Estacionamento }\end{array}$ & Sim & Sim & Não & - & - & PCT \\
\hline & Estacionamento & Sim & Sim & Sim & Não & - & VCT \\
\hline & Pedestre & Sim & Sim & $\operatorname{Sim}$ & Não & - & VCT \\
\hline & Sistema Viário & Sim & Não & - & - & - & DC \\
\hline & Visibilidade & Sim & Sim & Não & - & - & PCT \\
\hline & Loc. Imóvel/Via & Sim & Sim & Não & - & - & PCT \\
\hline & Transporte Urbano & Sim & Sim & Não & - & - & PCT \\
\hline \multirow{9}{*}{$\begin{array}{c}\text { Imóvel } \\
3\end{array}$} & Acesso Rua/Imóvel & Sim & Não & - & - & - & $\mathrm{DC}$ \\
\hline & $\begin{array}{l}\text { Aces. D.Física/M. } \\
\text { Red. }\end{array}$ & Não & - & - & - & - & $\mathrm{DC}$ \\
\hline & $\begin{array}{c}\text { Aces. } \\
\text { Estacionamento }\end{array}$ & Sim & Sim & Não & - & - & PCT \\
\hline & Estacionamento & Sim & Sim & $\operatorname{Sim}$ & Não & - & VCT \\
\hline & Pedestre & Sim & Sim & $\operatorname{Sim}$ & Não & - & VCT \\
\hline & Sistema Viário & Sim & Não & - & - & - & $\mathrm{DC}$ \\
\hline & Visibilidade & Sim & Não & - & - & - & $\mathrm{DC}$ \\
\hline & Loc. Imóvel/Via & Sim & Sim & Não & - & - & PCT \\
\hline & Transporte Urbano & Sim & Sim & Não & - & - & PCT \\
\hline
\end{tabular}

Continua 
Tabela 8 (continuação)

\begin{tabular}{|c|c|c|c|c|c|c|c|}
\hline & & \multirow{2}{*}{\multicolumn{6}{|c|}{ O recurso é: }} \\
\hline & & & & & & & \\
\hline Recurso & Variáveis Simbólicas & $\begin{array}{l}\text { Possuído } \\
\text { pela } \\
\text { Empresa }\end{array}$ & Valioso & Raro & $\begin{array}{c}\text { Difícil } \\
\text { de ser } \\
\text { imitado }\end{array}$ & $\begin{array}{l}\text { Difícil de } \\
\text { ser } \\
\text { substituído }\end{array}$ & $\begin{array}{l}\text { Implicações } \\
\text { Estratégicas }\end{array}$ \\
\hline \multirow{9}{*}{$\begin{array}{c}\text { Imóvel } \\
4\end{array}$} & Acesso Rua/Imóvel & Sim & Não & - & - & - & DC \\
\hline & $\begin{array}{l}\text { Aces. D.Física/M. } \\
\text { Red. }\end{array}$ & Não & - & - & - & - & DC \\
\hline & $\begin{array}{c}\text { Aces. } \\
\text { Estacionamento }\end{array}$ & Sim & Sim & Não & - & - & PCT \\
\hline & Estacionamento & Sim & Sim & Sim & Não & - & VCT \\
\hline & Pedestre & Sim & Sim & Sim & Não & - & VCT \\
\hline & Sistema Viário & Sim & Não & - & - & - & $\mathrm{DC}$ \\
\hline & Visibilidade & Sim & Não & - & - & - & DC \\
\hline & Loc. Imóvel/Via & Sim & Sim & Não & - & - & PCT \\
\hline & Transporte Urbano & Sim & Sim & Não & - & - & PCT \\
\hline
\end{tabular}

Nota. Fonte: Elaboração própria a partir dos dados coletados.

\section{Análises para os clientes do banco}

Para os 4 imóveis o acesso da rua/imóvel apresenta desvantagem competitiva, pois os degraus e escadas dificultam o acesso dos clientes com necessidades especiais e precisam ser adequados. Os 4 imóveis não possuem acesso para deficiente físico/mobilidade reduzida. No imóvel 1 é necessário a implantação de elevador, para os demais torna-se necessária a adequação do acesso existente. Os 4 imóveis apresentam paridade competitiva temporária para acesso ao estacionamento, pois existe agência concorrente nas proximidades com estacionamento próprio. O imóvel 1, para a variável estacionamento, apresenta paridade competitiva, pois possui estacionamento próprio, no mesmo imóvel e com número de vagas suficientes, diferentemente das agências dos bancos concorrentes nas proximidades, as quais não possuem estacionamento próprio no mesmo imóvel. Os imóveis 2,3 e 4 apresentam vantagem competitiva temporária, pois o estacionamento, apesar de ser terceirizado, é no próprio imóvel e nas proximidades existe agência concorrente com a mesma característica. O imóvel 1 apresenta paridade competitiva temporária para a variável pedestre, pois o mesmo possui travessia com semáforo, só que distante. Os demais imóveis apresentam vantagem competitiva temporária, pois a travessia com semáforo é próxima, o que não ocorre com agências concorrentes nas proximidades. Os 4 imóveis apresentam desvantagem competitiva para a variável sistema viário, pois as demais agências concorrentes estão localizadas em vias também denominadas coletoras. Os imóveis 1 e 2 apresentam paridade competitiva temporária para a variável visibilidade, pois são notados com facilidade pelos clientes. Os imóveis 3 e 4 apresentam desvantagem competitiva, pois eles não são notados com facilidade pelos clientes. Para os 4 imóveis a variável localização do imóvel/via apresenta paridade competitiva temporária, uma vez que eles estão localizados no mesmo sentido da via; entretanto agências concorrentes nas proximidades apresentam as mesmas características.

\section{Classificação dos imóveis em termos de vantagem competitiva}

Foi elaborada a Tabela 9, que possibilitou classificar os imóveis em termos de vantagem competitiva. Adotou-se como critério para a comparação deles a média ponderada, atribuindo-se pesos às implicações estratégicas, de acordo com sua ordem de importância. 
Tabela 9

Classificação dos Imóveis em Termos de Vantagem Competitiva

\begin{tabular}{|c|c|c|c|c|c|c|c|}
\hline Recurso & $\begin{array}{c}\text { Implicações } \\
\text { Estratégicas para as } \\
\text { políticas internas do } \\
\text { banco }\end{array}$ & $\begin{array}{c}\text { Total } \\
\text { Parcial }\end{array}$ & $\begin{array}{c}\text { Implicações } \\
\text { Estratégicas para } \\
\text { os clientes do } \\
\text { banco }\end{array}$ & $\begin{array}{c}\text { Total } \\
\text { Parcial }\end{array}$ & $\begin{array}{l}\text { Total } \\
\text { Geral }\end{array}$ & Pesos & $\begin{array}{c}\text { Média } \\
\text { Ponderada }\end{array}$ \\
\hline \multirow{5}{*}{ Imóvel 1} & $\begin{array}{c}\text { Desvantagem } \\
\text { Competitiva (DC) }\end{array}$ & 2 & $\begin{array}{c}\text { Desvantagem } \\
\text { Competitiva (DC) }\end{array}$ & 3 & 5 & 6 & \multirow{5}{*}{3,75} \\
\hline & $\begin{array}{c}\text { Paridade Competitiva } \\
\text { Temporária (PCT) }\end{array}$ & 6 & $\begin{array}{c}\text { Paridade } \\
\text { Competitiva } \\
\text { Temporária }(\mathrm{PCT})\end{array}$ & 5 & 11 & 7 & \\
\hline & $\begin{array}{c}\text { Vantagem } \\
\text { Competitiva } \\
\text { Temporária (VCT) }\end{array}$ & 2 & $\begin{array}{c}\text { Vantagem } \\
\text { Competitiva } \\
\text { Temporária (VCT) }\end{array}$ & - & 2 & 8 & \\
\hline & $\begin{array}{c}\text { Paridade } \\
\text { Competitiva (PC) }\end{array}$ & 2 & $\begin{array}{c}\text { Paridade } \\
\text { Competitiva (PC) }\end{array}$ & 1 & 3 & 9 & \\
\hline & $\begin{array}{c}\text { Vantagem } \\
\text { Competitiva } \\
\text { Sustentável (VCS) }\end{array}$ & - & $\begin{array}{c}\text { Vantagem } \\
\text { Competitiva } \\
\text { Sustentável (VCS) }\end{array}$ & - & 0 & 10 & \\
\hline \multirow{5}{*}{ Imóvel 2} & $\begin{array}{c}\text { Desvantagem } \\
\text { Competitiva (DC) }\end{array}$ & 3 & $\begin{array}{c}\text { Desvantagem } \\
\text { Competitiva (DC) }\end{array}$ & 3 & 6 & 6 & \multirow{5}{*}{3,52} \\
\hline & $\begin{array}{c}\text { Paridade Competitiva } \\
\text { Temporária (PCT) }\end{array}$ & 5 & $\begin{array}{c}\text { Paridade } \\
\text { Competitiva } \\
\text { Temporária }(\mathrm{PCT})\end{array}$ & 4 & 9 & 7 & \\
\hline & $\begin{array}{c}\text { Vantagem } \\
\text { Competitiva } \\
\text { Temporária (VCT) }\end{array}$ & 2 & $\begin{array}{c}\text { Vantagem } \\
\text { Competitiva } \\
\text { Temporária (VCT) }\end{array}$ & 2 & 4 & 8 & \\
\hline & $\begin{array}{c}\text { Paridade } \\
\text { Competitiva (PC) }\end{array}$ & 2 & $\begin{array}{c}\text { Paridade } \\
\text { Competitiva (PC) }\end{array}$ & - & 2 & 9 & \\
\hline & $\begin{array}{c}\text { Vantagem } \\
\text { Competitiva } \\
\text { Sustentável (VCS) }\end{array}$ & - & $\begin{array}{c}\text { Vantagem } \\
\text { Competitiva } \\
\text { Sustentável (VCS) }\end{array}$ & - & - & 10 & \\
\hline \multirow{5}{*}{ Imóvel 3} & $\begin{array}{c}\text { Desvantagem } \\
\text { Competitiva (DC) }\end{array}$ & 1 & $\begin{array}{c}\text { Desvantagem } \\
\text { Competitiva (DC) }\end{array}$ & 4 & 5 & 6 & \multirow{5}{*}{3,77} \\
\hline & $\begin{array}{c}\text { Paridade Competitiva } \\
\text { Temporária (PCT) }\end{array}$ & 8 & $\begin{array}{c}\text { Paridade } \\
\text { Competitiva } \\
\text { Temporária (PCT) }\end{array}$ & 3 & 11 & 7 & \\
\hline & $\begin{array}{c}\text { Vantagem } \\
\text { Competitiva } \\
\text { Temporária (VCT) }\end{array}$ & 1 & $\begin{array}{c}\text { Vantagem } \\
\text { Competitiva } \\
\text { Temporária (VCT) }\end{array}$ & 2 & 3 & 8 & \\
\hline & $\begin{array}{c}\text { Paridade } \\
\text { Competitiva (PC) }\end{array}$ & - & $\begin{array}{c}\text { Paridade } \\
\text { Competitiva (PC) }\end{array}$ & - & 0 & 9 & \\
\hline & $\begin{array}{c}\text { Vantagem } \\
\text { Competitiva } \\
\text { Sustentável (VCS) }\end{array}$ & 2 & $\begin{array}{c}\text { Vantagem } \\
\text { Competitiva } \\
\text { Sustentável (VCS) }\end{array}$ & - & 2 & 10 & \\
\hline
\end{tabular}

Continua 


\section{Tabela 9 (continuação)}

\begin{tabular}{|c|c|c|c|c|c|c|c|}
\hline Recurso & $\begin{array}{c}\text { Implicações } \\
\text { Estratégicas para as } \\
\text { políticas internas do } \\
\text { banco }\end{array}$ & $\begin{array}{c}\text { Total } \\
\text { Parcial }\end{array}$ & $\begin{array}{c}\text { Implicações } \\
\text { Estratégicas para } \\
\text { os clientes do } \\
\text { banco }\end{array}$ & $\begin{array}{c}\text { Total } \\
\text { Parcial }\end{array}$ & $\begin{array}{l}\text { Total } \\
\text { Geral }\end{array}$ & Pesos & $\begin{array}{c}\text { Média } \\
\text { Ponderada }\end{array}$ \\
\hline \multirow{5}{*}{ Imóvel 4} & $\begin{array}{c}\text { Desvantagem } \\
\text { Competitiva (DC) }\end{array}$ & 5 & $\begin{array}{c}\text { Desvantagem } \\
\text { Competitiva (DC) }\end{array}$ & 4 & 9 & 6 & \multirow{5}{*}{3,5} \\
\hline & $\begin{array}{c}\text { Paridade Competitiva } \\
\text { Temporária (PCT) }\end{array}$ & 7 & $\begin{array}{c}\text { Paridade } \\
\text { Competitiva } \\
\text { Temporária (PCT) }\end{array}$ & 3 & 10 & 7 & \\
\hline & $\begin{array}{c}\text { Vantagem } \\
\text { Competitiva } \\
\text { Temporária (VCT) }\end{array}$ & - & $\begin{array}{c}\text { Vantagem } \\
\text { Competitiva } \\
\text { Temporária (VCT) }\end{array}$ & 2 & 2 & 8 & \\
\hline & $\begin{array}{c}\text { Paridade } \\
\text { Competitiva (PC) }\end{array}$ & - & $\begin{array}{c}\text { Paridade } \\
\text { Competitiva (PC) }\end{array}$ & - & - & 9 & \\
\hline & $\begin{array}{c}\text { Vantagem } \\
\text { Competitiva } \\
\text { Sustentável (VCS) }\end{array}$ & - & $\begin{array}{c}\text { Vantagem } \\
\text { Competitiva } \\
\text { Sustentável (VCS) }\end{array}$ & - & - & 10 & \\
\hline
\end{tabular}

O imóvel 3 foi o que reuniu as melhores condições para implantação de uma nova agência bancária, seguido dos imóveis 1,2 e 4, respectivamente.

\section{Conclusões e Recomendações}

A identificação de um ponto comercial que atenda à configuração necessária para a implantação de agência bancária, é tarefa complexa que requer decisões estratégicas que necessitam de estudos criteriosos, e não apenas parâmetros baseados no bom senso e experiência dos especialistas. O sistema desenvolvido neste trabalho que consistiu na integração do Sistema de Informações Geográficas (SIG) com o Sistema Especialista (SE); foi denominado Sistema de Prospecção de Imóveis para o Setor Bancário (SPI). O SPI possibilitou subsidiar a tomada de decisão locacional, bem como detalhar as variáveis em termos de valor, raridade, dificuldade de serem imitadas e substituídas. Importa destacar que este não é fácil de ser imitado, pois exige conhecimento altamente especializado e multidisciplinar.

Foi oferecida aos especialistas do HSBC a comparação dos métodos costumeiramente utilizados pelo departamento de Administração de Imóveis (DAI) com o SPI.

Para tanto foram prospectados quatro imóveis disponíveis para locação no bairro Sítio Cercado, de modo a atender à configuração necessária na implantação de agência padrão. De acordo com o SPI, o imóvel 3 resultou como aquele que tem a melhor localização geográfica; pela visão baseada em recursos (VBR) foi o que reuniu as melhores condições para implantação de uma nova agência bancária, em termos de vantagem competitiva. É imprescindível destacar que a VBR eleva a capacidade de análise do SPI, pois vai além da questão de localização, ou seja, permite que os imóveis prospectados sejam examinados em termos de vantagem competitiva. Consequentemente, se efetuada pelo banco, a transação comercial referente à locação do melhor imóvel, este passaria a constituir novo recurso organizacional

De acordo com os especialistas, 'a utilização do sistema virá beneficiar de forma substancial o profissional envolvido com o trabalho, pois dará o necessário embasamento técnico para orientar a tomada de decisão locacional, uma vez que, devido ao grande número de informações que são 
necessárias para atender aos requisitos de alimentação do sistema, haverá certamente a redução do risco de contratação de imóveis não adequados aos objetivos traçados pela empresa'.

Como sugestões para a continuidade deste trabalho destacam-se os itens abaixo.

1. Considerar, além de dados socioeconômicos e mapeamento da concorrência, a definição da delimitação da área de influência das agências, a fim de identificar locais de atendimento sem cobertura ou até mesmo com sobreposição. Esta seria, portanto, mais uma variável espacial a ser considerada, auxiliando na seleção da região. Entretanto uma das dificuldades em tratar com esta variável é que, para a sua configuração, podem ser necessários dados sigilosos, como os endereços dos clientes de cada agência.

2. Implementar opções para emissão de relatórios dos dados analisados para cada imóvel prospectado, bem como opções para a geração de gráficos referentes à pontuação alcançada por cada imóvel prospectado.

3. Implementar um sistema de Avaliação da Conformidade Técnica, Legal e de Localização da rede de agências bancárias por meio da integração do Sistema de Informações Geográficas e Sistema Especialista.

Como recomendações destaca-se que a base de conhecimentos do SE pode ser aumentada, considerando informações referentes à documentação do imóvel prospectado, como estas: projeto de construção aprovado pela Prefeitura; projeto de reforma aprovado pela Prefeitura; Imposto Predial e Territorial Urbano (IPTU); e Matrícula do Registro de Imóveis, entre outros. As informações referentes às documentações do imóvel, uma vez analisadas simultaneamente com valor de mercado, área, número de pavimentos do imóvel, entre outros, serviria no caso da não conformidade legal para inviabilizar o imóvel.

Artigo recebido em 11.05.2009. Aprovado em 26.10.2010.

\section{Agradecimentos}

Em especial ao Prof. Dr. Sergio Bulgacov (Pós-Graduação em Administração - UFPR) pela inestimável colaboração, sem a qual não teria sido possível a idealização do artigo. À Coordenação de Aperfeiçoamento de Pessoal de Nível Superior (CAPES) pela concessão da bolsa. Ao HSBC Bank Brasil S/A - Departamento de Administração de Imóveis pela colaboração no desenvolvimento do trabalho.

\section{Referências}

Barney, J. (1991). Firm resources and sustained competitive advantage. Journal of Management, 17(1), 99-120.

Barney, J. (1992). Integrating organizational behavior and strategy formulation research: a resourcebased analysis. In P. Shrivastava, A. S. Huff, \& J. E. Dutton (Eds.), Advances in strategic management (Vol. 8, pp. 203-227). Greenwich: Jai Press.

Barney, J. (1994). Commentary: a hierarchy of corporate resources (A. L. Brumagin). In P. Shrivastava, A. S. Huff, \& J. E. Dutton (Eds.), Advances in strategic management (Vol. 10/A, pp. 113-125). Greenwich: Jai Press.

Barney, J. (1996). Gaining and sustaining competitive advantage. Reading, MA: Adisson Wesley. 
Barney, J., \& Hesterly, W. (1996). Organizational economics: understanding the relationship between organizations and economic analysis. In S. R. Clegg, C. Hardy, \& W. R. Nord (Eds.), Handbook of organization studies (pp. 115-147). London: Sage Publications.

Bittencourt, G. (1998). Inteligência artificial: ferramentas e teorias. Florianópolis: Ed. da UFSC.

Burrough, P. A., \& McDonnell, R. A. (1998). Principles of geographical information system for land resource assessment. Oxford: Claderon Press.

Câmara, G., \& Queiroz, G. R. (2006). Arquitetura de sistemas de informações geográficas. In G. Câmara, A. M. Monteiro, \& C. Davis (Eds.), Introdução à ciência da geoinformação. Recuperado em 12 maio, 2006, de http://www.dpi.inpe.br/gilberto/livro

Carnasciali, A. M. S. (2007). Integração de sistemas de informações geográficas e sistema especialista visando auxiliar a tomada de decisão locacional do setor bancário. Dissertação de mestrado, Universidade Federal do Paraná, Curitiba, PR, Brasil.

Cowen, D. J. (1988). GIS versus CAD versus DBMS: what are the differences. Photogrammetric Engineering and Remote Sensing, 54(1), 1551-1554.

Durkin, J. (1994). Expert systems: design and development. New York: Macmillan Publishing Company.

Eldrandaly, K., Eldin, N., \& Sui, D. (2003). A COM-based spatial decision support system for industrial site selection. Journal of Geographic Information and Decision Analysis, 7(2), 72-92.

Genaro, S. (1986). Sistema especialista: o conhecimento artificial. Rio de Janeiro: Livros Técnicos e Científicos Editora S.A.

Grant, R. M. (1996). Contemporary strategy analysis: concepts, techniques, applications. Cambridge, MA: Blackwell Business.

Harmon, P., \& King, D. (1988). Sistemas especialistas. Rio de Janeiro: Campus.

Liao, S. (2005). Expert system methodologies and applications - a decade review from 1995 to 2004. Expert Systems with Applications, 28, 93-103. doi:10.1016/j.eswa.2004.08.003

Peteraf, M. A. (1993). The cornerstones of competitive advantage: resource-based view. Strategic Management Journal, 14(3), 179-191.

Porter, M. (1986). Estratégia competitiva: técnicas para análise de indústrias e da concorrência. Rio de Janeiro: Campus.

Porter, M. (1991). Towards a dynamic theory of strategy. Strategic Management Journal, 12(Summer Special Issue), 95-117.

Porter, M. (1996). What is strategy? Harvard Business Review, 11(12), 61-78.

Waterman, D. A. (1983). Building expert systems. Canadá: Addison-Wesley Publishing Company, Inc.

Waterman, D. A. (1986). A guide to expert systems. Canadá: Addison-Wesley Publishing Company, Inc.

Wernerfelt, B. (1984). A resource-based view of the firm. Strategic Management Journal, 5(2), 171180. 